\title{
Modelos de autoridad y nuevas formas de representación en la literatura centroamericana ${ }^{1}$
}

\section{Albino Chacón Gutiérrez²}

\author{
Universidad Nacional, Costa Rica
}

\begin{abstract}
resumen
A partir de un variado corpus de narrativa contemporánea centroamericana, se describen y analizan procesos de transformación de la idea y ejercicio de lo literario. Se dedica atención a sucesivas modalidades como el testimonio, la literatura de posguerra, la novela neohistórica y la literatura gay/ lésbica, como alternativa escriturales. A lo largo de un periodo de más de tres decenios — desde 1976 hasta la actualidad - se pone en entredicho tanto el canon literario tradicional como la autoridad que han ejercido los proyectos políticos hasta hace poco todavía vigentes.
\end{abstract}

\begin{abstract}
Based on a varied corpus of contemporary Central American narrative, a discussion is presented here of how the concept and practice of literary expression is transformed. Attention is given to the successive alternatives of testimonial literature, postwar writing, the historical novel and gay/lesbian literature. For three decades - from 1976 to present - the validity of the traditional literary canon and authority prevalent until very recently has been questioned.
\end{abstract}

Palabras clave: novela centroamericana, novela política, literatura testimonial, literatura de posguerra, novela neohistórica, literatura gay/lésbica Keywords: Central American novel, political novel, testimonial literature, postwar literature, neohistorical novel, gay/lesbian literature

1 Conferencia de apertura del XX Congreso Internacional de Literatura Centroamericana (ciLca) 2012. Recibido: 3 de diciembre de 2010; aceptado: 12 de enero de 2011.

2 Facultad de Filosofía y Letras. Correo electrónico: achacon@una.ac.cr.

$$
L_{\text {etras }} 49 \text { (2011), ISSN 1409-424X }
$$


La publicación de la novela Los compañeros, en 1976, del guatemalteco Marco Antonio Flores, marca un parteaguas de los modelos de escritura imperantes hasta entonces en Centroamérica, al mostrar por primera vez los meandros internos y las voces secretas, privadas, de los grupos que entonces llevaban a cabo la lucha armada revolucionaria en ese país ${ }^{3}$. Ello se logra a partir de una distancia caracterizada literariamente por la ironía, la parodia, una extremada violencia lingüística y un aparente caos en la arquitectura textual, recursos con los que, performativamente, busca dar cuenta del desconcierto interno que entonces vivían los movimientos y sujetos participantes en la lucha armada contra las fuerzas gubernamentales.

Bien podría considerarse que Los compañeros se convierte en un texto de desautorización de un modelo entonces dominante como paradigma de escritura, no solo literario sino también moral; me refiero al testimonio. El desconcierto que se respira en la obra expresa una atmósfera de época: el surgimiento de una conciencia acerca del fracaso de los proyectos políticos revolucionarios de la época, que habían enarbolado en los medios intelectuales los ideales de justicia social y, como razón última, la eliminación de los regímenes despóticos que hasta entonces habían atravesado la historia del país.

Los compañeros fue escrita después de diez años de militancia del autor y su participación en las estructuras del Partido Guatemalteco del Trabajo (PGT). Luego se produce el rompimiento, y a raíz de este nace la novela. Sorprende el año de publicación (1976), pues la visión crítica que esta lanza sobre la subjetividad de los actores de la guerrilla urbana y su tratamiento como seres llenos de contradicciones, debilidades e intereses personales está muy lejos de cualquier visión heroica, en un período en que los enfrentamientos militares estaban en todo su apogeo y la represión gubernamental era especialmente fuerte.

3 Marco Antonio FTores, Los compañeros (México: Editorial Joaquín Mortiz, 1976). 
El asesinato del poeta salvadoreño Roque Dalton, enjuiciado y ejecutado a tiros por parte de sus propios compañeros, en 1975, así como las oscuras circunstancias de la muerte de los comandantes Salvador Cayetano Carpio (Marcial) y Mélida Anaya Montes (Ana María), también salvadoreños, en 1983, en Managua, son acciones que se podrían enumerar acerca del desconcierto, el desánimo y la frustración que se apoderó de los hasta entonces incontestables movimientos de la izquierda centroamericana en el cruce de las décadas de 1970 y 1980 , pero también de las sangrientas luchas de poder y de traición que en su interior anidaban los grupos que se habían autoerigido como las autoridades morales y políticas de la izquierda centroamericana.

Esas circunstancias produjeron fisuras y un quiebre tan profundo en la percepción y funcionamiento de los grupos de izquierda, que aún hoy siguen marcando la política de la región, y en lo que a nosotros nos concierne de manera particular, la perspectiva que de lo político se escenifica en la literatura. Esa pérdida de la autoridad moral y de la escritura que supuestamente la traducía en términos literarios, produjo una literatura del desencanto, del cinismo, expresada sobre todo en la narrativa, en la llamada «literatura de posguerra $»^{4}$, con su mirada irónica, sarcástica, incluso cáustica, sobre las figuras emblemáticas de ese período, sobre los hechos y sus motivaciones, tanto sociales como psicológicas, que estuvieron detrás de muchos de los acontecimientos sucedidos. Un ejemplo que ilustra lo que quiero decir sobre este ambiente de época es la novela Sopa de caracol (2003), del guatemalteco Arturo Arias; novela conversacional que transcurre durante una cena en la que un exmilitante de izquierda se decide a contar su historia personal llena de culpas y a ofrecerse él mismo como platillo, para ser devorado a manera de expiación.

Ninguno de los protagonistas puede aducir inocencia. ¿En quién confiar? ¿Qué proyecto alternativo podía ser construido que tomara el relevo de una autoridad moral y estética que se resquebrajaba

4 Véase a este respecto el excelente estudio de Beatriz Cortés, Estética del cinismo. Pasión y desencanto en la literatura centroamericana de posguerra (Guatemala: F\&G Editores, 2010). 
a pedazos? Quizás por eso en la novelística de la posguerra no hay nostalgia ni pretensiones heroicas de los protagonistas; solo escenarios en que todo parece funcionar de manera violenta y sin horizontes claros en cuanto a un proyecto viable de sociedad. La novela iniciática por antonomasia de este período, la ya mencionada Los compañeros, es el texto que inaugura el tratamiento antiutópico en la narrativa centroamericana, al recurrir a una estética diametralmente opuesta a la seguida por la literatura testimonial de los años sesenta y setenta, y que aún, cabe aclarar, continuará escribiéndose en los ochenta ${ }^{5}$. De modo violento, una nueva manera de hacer novela quedaba inaugurada en la narrativa regional ${ }^{6}$. La literatura centroamericana rompía con la autoridad estética del espejo realista y de denuncia optimista, promotora de cambios sociales, que la había identificado y moldeado en buena parte del siglo xx. Como lo expresa W. Mackenbach, en la introducción de la antología de cuentos Cicatrices. Un retrato del cuento centroamericano ${ }^{7}$ :

Las grandes propuestas colectivas utópicas han cedido ante una mirada crítica sobre el morir y matar individual [...]. No es tema de esta narrativa breve la reconstrucción de una identidad nacional o colectiva a través de la construcción de un proyecto revolucionario, sino más bien la confrontación con la múltiple y caótica realidad luego del fracaso de los proyectos sociales y políticos.

5 Para más información sobre la novela testimonial: Ivana Barboza, Hogar y nación en el género literario testimonial centroamericano: El caso de «Me llamo Rigoberta Menchú y así me nació la conciencia» y el caso de «Este es mi testimonio: María Teresa Tula, luchadora pro derechos humanos de El Salvador». Tesis para obtener el grado de Magíster en Letras (Universidad Nacional. Heredia, Costa Rica, 2000).

6 Seymour Menton indica las diferencias entre la novela histórica tradicional y la «nueva novela histórica». Ver La nueva novela histórica de la América Latina, 1979-1992 (México: Fondo de Cultura Económica, 1993), en especial p. 42 y ss.

7 Werner Mackenbach, «Introducción» a Cicatrices. Un retrato del cuento centroamericano (Managua: Anama, 2004) 18; y cfr. «La nueva novela histórica en Nicaragua y Centroamérica», Istmo. Revista virtual de estudios literarios y culturales centroamericanos 1 (2001). 
La siguiente novela de Flores, En el filo (1993), continúa esa misma línea temática, un decenio después de la derrota que el ejército infringió a las organizaciones guerrilleras de Guatemala ${ }^{8}$. Se disecciona esa derrota, al tomar como base de la narración a una organización guerrillera, perseguida y desarticulada por la sección de inteligencia militar G-2, gracias a la colaboración de El Tigre, un jefe revolucionario corrupto y traidor, que conoce toda la estructura y desencadena una serie de delaciones, traiciones y represiones, luego de que cae en una redada policial. La narración de la violencia física y psicológica que se respira, encuentra su correlato en el derroche verbal de un léxico erótico, soez, violento que muestran los personajes y también el narrador. En cierta manera, el principio obedece a que, si la guerra agrede, la novela también busca hacerlo, tanto por los contenidos como por la manera de narrarlos y la atmósfera que se crea. En el filo, novela de antihéroes, plantea una crítica profunda a la descomposición sufrida por los grupos guerrilleros y a la caída del idealismo vividas durante esos años y que habían motivado el surgimiento de la guerrilla. El epígrafe de otra de sus novelas, Las batallas perdidas (1999), resume y expresa la imposibilidad de las identidades políticas y de sus puntos de autoridad tradicionales: «Destruyéndonos. Así hemos vivido. Como entre una alucinación lo íbamos violentando todo. No sabíamos ordenar nuestro destino».

El héroe tradicional que carga sobre sí una tarea, una utopía o la realización de una acción marcada por determinaciones éticas, históricas, políticas o morales parece desvanecerse; de ahí la indolencia de los personajes, que define una visión desencantada acerca de la vida, de la vida política, pero también acerca de la vida a secas y de cualquier valor moral que la sostenga. Esta novelística desencadena una confrontación de carácter textual en la región, pues surge cuando aún se consideraba la literatura como arma de combate en la lucha política. En la orilla de esta literatura utópica tendríamos, por citar

8 Marco Antonio Flores. En el filo, 3.a ed. (Guatemala: F\&G Editores, 1993/2002). 
tres casos notables, al salvadoreño Manlio Argueta, con Un día en la vida y al guatemalteco Mario Payeras, con Los días de la selva, ambas publicadas cuatro años después, en 1980, y luego en 1983 la publicación de Me llamo Rigoberta Menchú y así me nació la conciencia, que habría de convertirse en la obra emblema de la producción testimonial centroamericana por su doble carácter político y étnico, y a partir de la cual Menchú se transformaría en la autoridad indiscutida de las reivindicaciones indígenas de la región hasta recibir el premio Nobel de la paz en 1992, coincidiendo con la celebración oficial del quinto centenario de la llegada de los españoles aAmérica.

En la década de 1980 esa lucha textual se decantó en favor del concepto de literatura como arma ideológica de combate. Pero detengámonos en este funcionamiento de los años sesenta y setenta, período en que la forma literaria que predominó ampliamente sería la testimonial. Antes de Argueta, Payeras y Menchú, Ana Guadalupe Martínez publicó en 1979, en México, su testimonio Las cárceles clandestinas de El Salvador. Miguel Mármol, de Roque Dalton, se publicó en 1982. Luego vendría Claribel Alegría, con No me agarran viva: la mujer salvadoreña en la lucha, escrita en colaboración con Darwin J. Flakoll, de 1983, y Para romper el silencio: resistencia y lucha en la cárceles salvadoreñas, de 1984. Asimismo, el testimonio Nunca estuve sola, de la salvadoreña Nidia Díaz, de 1988, y el más reciente caso de Este es mi testimonio. María Teresa Tula, luchadora proderechos humanos de El Salvador, de Tula y de la norteamericana Lynn Stephen como su editora. Me interesa de manera particular este último caso porque, en una situación semejante a la de Burgos con Menchú, pero sin generarse conflictos por ello, en el caso del testimonio de Tula, Lynn Stephen tuvo a cargo el trabajo de investigación, traducción y edición del libro, que apareció publicado primero en inglés en 1994. La publicación en español es de 1995, y es una traducción de la original. Pero Tula y Menchú no son los únicos casos de intervención de una intelectual extranjera productora del texto. La guatemalteca Yolanda Colom escribió Mujeres en la 
alborada, publicado en 1998, pero fue escrito a inicios de la década de 1990 por iniciativa y estímulo de Norma Stoltz, profesora del programa sobre estudios de la mujer en la Universidad Estatal de California, y de Bobbye Ortiz, activista feminista editora de Monthly Review. A pesar de que la literatura de ficción ya había tomado otros rumbos, el testimonio, por su fuerza política, moral y de reconstrucción de la memoria fue tal que, aun a finales de siglo se siguieron produciendo, aunque ya no en la misma cantidad de antes, gracias al reconocimiento de que gozó en las décadas pasadas, al ser considerado como la marca de fábrica de la literatura centroamericana9 ${ }^{9}$.

Detengámonos en la historia, sobre todo en el modo como se produjeron los textos testimoniales, de manera particular en tres aspectos que vale la pena destacar para los efectos de esta jornada. En primer lugar, el papel que desempeñó la academia norteamericana en la visibilización internacional del testimonio centroamericano y su ingreso dentro del canon académico universitario de los Estados Unidos; en efecto, antes que leído en los medios intelectuales y culturales centroamericanos, el testimonio de Menchú ya lo leían los estudiantes de universidades norteamericanas. No hay que olvidar que fue también en ese medio académico donde se dio a conocer internacionalmente la mencionada novela de Argueta, Un día en la vida. La literatura centroamericana estrictamente de ficción no despertó en la academia norteamericana el mismo interés que ocurrió con el testimonio. Un sector de esa academia conserva aún esa visión del testimonio en los coloquios y congresos sobre literatura centroamericana. ¿Por qué? Me atrevo a afirmar que se debe a que se trataría de la literatura que expresa la condición de países neocoloniales, dentro de una visión metropolitana cuyo discurso crítico se atribuye la definición, posibilidades y funcionamiento de la producción literaria de la región. El tipo de estudios que llevan a cabo en los congresos y coloquios así lo muestra. La crítica literaria hecha desde la academia

9 Cfr. Jorge Román-Lagunas (comp.), Visiones y revisiones de la literatura centroamericana (Guatemala: Editorial Óscar de León Palacios, 2000). 
norteamericana se erigió durante muchos años como el referente de autoridad de lo que era la literatura centroamericana. Mucha de la crítica producida en la región siguió ese modelo externo.

En segundo lugar, es de notar la abrumadora presencia de testimonios escritos por mujeres. Ciertamente, no se trata de una característica solo de la producción testimonial, sino de la producción literaria en general, con lo que la autoridad autorial y la perspectiva de la literatura como actividad típicamente masculina, dominante hasta entonces, se rompió. En efecto, el panorama literario centroamericano de los últimos años muestra una fuerte presencia de escritoras que, en el caso de Costa Rica, han llevado a Carmen Naranjo, una de las principales figuras de las letras costarricenses, a hablar de un matriarcado en las letras de su país.

En tercer lugar, la dominancia del código realista que caracterizó esta producción, a la cual ya he hecho alguna referencia. Dicho código marcó, por una parte, una alta referencialidad política; por otra, la función de reconstrucción histórica de la experiencia vivida, mediante la interpretación de esa inmediatez aportada por el género testimonial en sus diversas variantes: «testimonio», «literatura testimonial», «literatura documental» que se desarrolló de manera particular en Guatemala, El Salvador y Nicaragua. La intención del testimonio $-\mathrm{y}$ esto nos lleva a otro aspecto interesante de la caída de un modelo literario - nunca fue constituir, de entrada, un texto literario, sobre todo si tomamos en cuenta que muchos fueron escritos por personas que no habían tenido previamente ninguna experiencia con la escritura, menos aun con la escritura de libros. Muchos de esos libros fueron escritos gracias a la presencia y sobre todo la autoridad de mujeres intelectuales que trabajaron la arquitectura de los textos con esas mujeres no escritoras, sobre todo provenientes de universidades provenientes de fuera de la región: Elizabeth Burgos, Lynn Stephen, Norma Stoltz, Bobbye Ortiz. No olvidemos que fue precisamente una académica norteamericana de la Universidad de Nuevo México, Margaret Randall, quien redactó Qué es y cómo se 
hace un testimonio, el conocido manual de tanta influencia de esos años sobre cómo escribir testimonios, preparado en 1979 para el taller sobre historia oral del Ministerio de Cultura Sandinista ${ }^{10}$. Por otra parte, los grandes teóricos de la producción testimonial, considerados autoridades por antonomasia, son los también académicos norteamericanos John Beverley y Marc Zimmerman. Con lo anterior, quiero dejar claro el papel que ha desempeñado la autoridad de la academia y de sus intelectuales, de manera particular la norteamericana, en la producción literaria, en la crítica literaria y en la academia centroamericana.

El testimonio constituyó el género que identifica la literatura de la época, por su fuerte relación con el contexto social, la utilización de recursos de la oralidad narrativa y la utilización del relato etnográfico como modelo. Es posible considerar que esta última característica, sumamente importante en la conformación estructural del género, así como en el programa de lectura que provoca y tipo de conocimiento que produce, sea más bien propia del segundo sujeto de la escritura, es decir, un producto de los agentes que se hicieron cargo de la planificación y arquitectura textual de los testimonios, e incluso de su ingeniería, si no de su concepción misma. Debe tenerse presente que los testimonios pertenecen a la categoría de los textos de escritura intervenida; muy probablemente son también el resultado de una voz igualmente intervenida, dirigida, regentada e incluso tutelada (por motivaciones, cuestionarios, preguntas, temas sugeridos, énfasis, etc.). Esta estrategia de concepción y producción debe tenerse en cuenta e integrarse a lo expresado mediante los testimonios que, por su alto contenido referencial y su función política, se resisten a ser leídos y estudiados en su sola concreción textual. Los testimonios desempeñaron el papel de espejos de un momento histórico determinado, dada la legitimidad y autoridad social de la

10 Margaret Randall, Qué es y cómo se escribe un testimonio (Managua: Ministerio de Cultura Sandinista, 1976). Edición consultada: Revista de Crítica Literaria Latinoamericana XVIII, 36 (1992): 23-47. 
voz narrativa, protagonista privilegiada de los acontecimientos narrados, así como el alto valor representativo social que se le concede.

El caso de La montaña es algo más que una inmensa estepa verde, ganador del Premio Casa de las Américas en 1982, del nicaragüense Omar Cabezas ${ }^{11}$, ocupa un lugar interesante en la producción testimonial, pues se aleja de la estética y tratamiento de los testimonios que se estaban escribiendo en ese momento en El Salvador y en Guatemala. Cabezas grabó numerosas cintas, durante unas veinte horas, sobre sus años de militancia, que después editó para componer el testimonio. Se trata de un texto escrito en un estilo espontáneo, vívido, proveniente de la utilización del lenguaje oral, lleno de humor y con un tono a menudo incluso carnavalesco, sobre la experiencia vivida por un guerrillero combatiente del Frente Sandinista de Liberación Nacional durante la lucha contra la dictadura somocista. En esto pudo haber influido que ya la guerra en Nicaragua había finalizado, lo que permitía una recreación de la vivencia guerrillera de una manera menos canónica y más lúdica, característica esta última que estuvo ausente en la producción testimonial anterior. Dada la función social que le tocaba desempeñar, lo lúdico no cabía en él. Por aspectos como los mencionados, La montaña es algo más que una inmensa estepa verde se desmarca estructuralmente de los otros testimonios de la época y en cierta manera rompe el espejo hasta entonces prevaleciente de un género, por lo demás, muy fijo en sus reglas de elaboración.

En suma, la novelística centroamericana de los años ochenta, sobre todo a partir de los noventa, se debatió entre las propuestas éticas y estéticas de los planteamientos revolucionarios, por una parte, articuladas sobre todo en la producción testimonial y la mirada que esta lanzaba sobre acontecimientos recién vividos y sujetos y fuerzas aún vigentes; y por otra, la influencia que pronto comenzó a ejercer la estética inaugurada en la región por la novela Los compañeros y

11 Omar Cabezas, La montaña es algo más que una inmensa estepa verde (Managua: Editorial Nueva Nicaragua 1982). 
que daría origen a un verdadero boom de la narrativa centroamericana, al volver los ojos, en contraposición radical a la autoridad del modelo anterior, al carácter ficcional como valor creativo, con un programa de escritura diametralmente distinto al carácter etnorrealista de la narrativa anterior. Sujetos y temas que esta última había dejado de lado, toman un protagonismo inédito, como es el caso de la sensibilidad femenina, el erotismo, la literatura gay, así como la nueva violencia, ligada no a justificaciones políticas, sino a la violencia de la cotidianidad citadina, de soldados y guerrilleros, muchos de ellos reciclados como delincuentes citadinos.

La nueva literatura, denominada «literatura de posguerra»o literatura posrevolucionaria, no apunta a una determinación temporal. Si bien continúa articulándose alrededor del tema de la guerra, sus sujetos y sus consecuencias, lo hace sin expresar explícitamente o plantearse como portadora de un programa ideológico político particular. Es el caso de Managua Salsa City, idevórame otra vez! (2000), del nica-guatemalteco Franz Galich, sobre las andanzas de un exguerrillero sandinista en las noches de Managua, y de El arma en el hombre (2001), del salvadoreño Horacio Castellanos, sobre los crímenes y extrema violencia de un exmilitar salvadoreño desempleado. O bien, como es el caso de la mencionada Sopa de caracol (2003), de Arias, no con la violencia escénica de las novelas mencionadas, pero escrita con una gran dosis de cinismo, irreverencia e impudor ideológico al pasar revista el narrador a su pasada militancia guerrillera. Podemos obtener como corolario de todo esto que la autoridad del proyecto político de la izquierda y su influencia en la producción literaria se derrumba al empezar la década de 1990.

Junto con la literatura de posguerra se escribe también una novelística neohistórica ${ }^{12}$. Entendemos esta como aquella novelística reciente que toma como nudo fundamental la revisión crítica de la autoridad del discurso histórico en relación con la construcción de las 12 ValeriaGrinbergPla, «La novelahistórica de finales del sigloxx y lasnuevascorrienteshistoriográficas», Istmo. Revista virtual de estudios literarios y culturales centroamericanos 2 (2001). 
identidades nacionales y sus ejes de articulación. Sobre el período colonial, o haciendo emerger nuevos sujetos (mujeres, negros); en suma, el cuestionamiento de las nociones fijas de las identidades nacionales históricas como categorías fuertes, procediendo a una rearticulación de estas, o bien escenificando su pérdida como referente histórico único. No hay en esta nueva narrativa una reproducción mimética del pasado, como lo intentó la novela de la primera mitad de siglo, período en que funcionaba como una producción literaria ancilar de otro género que funcionaba como referente de autoridad, el histórico o, en el caso del testimonio, su autoridad etnológico-histórica reposaba en su condición de expresión auténtica de una realidad.

Ha aparecido también una nueva serie textual o conjunto discursivo de alcance regional, en un ámbito hasta ahora muy poco estudiado en Centroamérica, fundamental porque se trata de un caso de resituación del tema de las identidades en ámbitos particulares de grupos determinados, fuera de la categoría general de las identidades nacionales: la literatura gay/lésbica ${ }^{13}$. El valor enunciativo de esta literatura plantea una relectura frontal de los referentes de autoridad del Estado, del papel de sus instituciones, y en cuanto al libro literario como espacio privilegiado de condensación de las contradicciones sociales y de las luchas ideológicas que tienen que ver con la política de los cuerpos. Esto es, el cuerpo como un lugar central dentro de la socialidad, espacio de representaciones y de funcionamiento por cuyo control luchan diversas instituciones, desde la autoridad del Estado hasta la autoridad religiosa, personificada tradicionalmente en la Iglesia Católica, pero hoy también por diversas confesiones pentecostales de creciente influencia en los países de la región, frente a las cuales, más que otras manifestaciones artísticas y sociales, parece levantarse con especial fuerza la literatura.

El estudio de esta producción se torna ineludible para una mejor comprensión del funcionamiento de las nuevas identidades

13 Por ejemplo, ver: Alexander Obando, La gruta y el arco iris. Antología de narrativa gay/lésbica costarricense (San José: Editorial Costa Rica, 2008). 
particulares, que se muestran en los espacios públicos de nuestras sociedades a partir de los últimos treinta años, en un principio con solo algunos tímidos intentos en el tratamiento literario de las manifestaciones sexuales más allá de la heterosexualidad marital. Se trataba de elementos incitadores de una transgresión que, al decir del historiador de la literatura costarricense Álvaro Quesada Soto, conducía en el texto, según la lectura de la época, a «la descomposición social y a la pérdida de la identidad nacional, asociada a la desintegración del núcleo familiar oligárquico-patriarcal», a «la disolución y corrupción de los valores y vínculos tradicionales» ${ }^{14}$.

Teníamos que llegar a las últimas décadas del siglo xx para que, de alusiones que marginalizaban aun más todo lo que tuviera que ver con la sexualidad, se pasara a una nueva manera de tratar, no solo el tema de la homosexualidad, sino en general la sexualidad misma, lo cual indica la estricta política de control que las sociedades centroamericanas habían ejercido sobre el cuerpo. De la misma manera que el indígena, para integrarse socialmente, se ha visto obligado a «desindigenizarse», las minorías sexuales se veían obligadas a «desexualizarse», sobre todo en el plano de lo público. No se trata de una situación coyuntural, sino de una política de disciplinamiento y de eliminación de la diferencia que la literatura recogió y mostró. Obras recientes publicadas nos hablan de cuerpos y de nuevas identidades sexuales, pero tratándose de literatura, podemos hablar de la descripción/inscripción de esos cuerpos en libros que ofrecen una imagen plural, con sus distorsiones y aciertos, flexiones y contornos, y de cómo esos cuerpos - y el cuerpo social como un todo - se han ido moldeando en los pliegues de la historia cultural centroamericana, en una especie de memoria literaria de la sexualidad en la región a través del siglo xx. Esta constatación debería tener un profundo valor para una mejor comprensión de algo que aún no se ha construido en la región, el conocimiento e investigación de la sexualidad en la

14 Álvaro Quesada Soto, Breve historia de la literatura costarricense (San José: Editorial Costa Rica, 2008) 27 y 30. 
historia cultural centroamericana y de sus formas de autorrepresentación y de construcción discursiva.

Esas son algunas de las líneas que caracterizan lo principal de la producción novelesca centroamericana de los últimos treinta años y su relación con las diversas posibilidades de trabajo que ofrece la noción de autoridad, en campos de trabajo que van desde la colonia, los años de formación de los estados nacionales, el papel de grupos o de sujetos marginales dentro de la conformación de las heterogéneas identidades de los países centroamericanos, así como los grandes hitos que atravesaron la historia regional relativamente reciente, tales como las dictaduras a lo largo de todo el siglo, los conflictos armados a que dieron lugar y la descomposición política. La novela contemporánea centroamericana cumple, de esa manera, una nueva función, muy distinta a la función de cimentadora de valores y de significaciones de verdad que desempeñó en épocas pasadas. De ahí se comprenderá entonces lo que mencionamos al principio, de considerar a esa nueva literatura, no como conformadora de autoridad, sino más bien como una producción desautorizadota de construcciones previas.

El espejo se rompió y hoy esos fragmentos recrean dentro del espacio literario las diversidades que el concepto de identidad nacional tenía soterradas; de ahí la violencia en la eclosión, frente a un estado o estados cuya cohesión interna se ha mantenido sobre muy débiles bases, prueba de cuya debilidad ha sido la violencia represiva en sus diversas manifestaciones sociales. Hoy, el futuro de nuestras sociedades como sociedades viables pasa por la revisión de un funcionamiento de las instituciones estatales que, ancladas en un viejo orden, siguen afrontando dificultades para renovarse y generar nuevos y necesarios lazos de identidad y solidaridad de ese lugar en construcción llamado Centroamérica y que aún no sabemos qué es o qué, con exactitud, quiere decir. 